\title{
ASSESSING THE RETURNS TO SCALE: EVIDENCE FROM FISH FARMERS IN ILORIN, KWARA STATE
}

\author{
N.A. Jatto, Researcher \\ Department of Agricultural Economics, Usmanu Danfodiyo University, Nigeria \\ E-mail: nuayjao@yahoo.com
}

\begin{abstract}
This study assesses the returns to scale as evidenced from fish farmers in llorin, Kwara. A random sampling technique was adopted in selecting 120 fish farmers from fish farmers association of Nigeria llorin branch list. The data for the study were collected with the use of well structured questionnaire. The result showed the fish farmers were relatively technically efficient in their use of resources, with a mean technical inefficiency of $40 \%$. The result also showed that $73 \%$ of the fish farmers exhibited increasing returns to scale. On the average; numbers of fingerlings, feeds and labour had slacks of $0.0,6.5$ and 0.4 respectively. These imply that inputs could be decreased by those units and still produce the same level of output. Thus, the fish farmers are said to be inefficient in input usage by the said values. It was concluded that though average cost is expected to decrease as output increases there is still room for improvement in productivity of fish farms. With this high level of returns to scale in fish farming, it is recommended that this information should be spread to all the farmers in the study area and other surrounding communities.
\end{abstract}

\section{KEYWORDS}

Returns to scale; Data envelopment analysis; Fish farmers.

Returns to scale refer to the degree by which level of production changes as a result of given change in the level of all inputs used. Salvatore (1996) stated that there are three different types of returns to scale: constant return to scale (CRS) means when we double all inputs, output is exactly doubled, increasing return to scale (IRS) means when we double all inputs, output is more than doubled and decreasing return to scale (DRS) means when we double all inputs, output is less than doubled. Mathematically, the implication of returns to scale can be shown as follow. Let denote a production function as $Q=f(K, L)$. If $K$ and $L$ is multiplied by, and then $Q$ increases by as indicated in $Q=f(K, L)$. The production function exhibits CRS, IRS or DRS respectively, is dependent on whether $=$, $>$ or $<$.

To determine returns to scale of fish farmers, a data envelopment analysis model was used in this study. It has long been recognized that data envelopment analysis (DEA) by its use of mathematical programming is particularly adept at estimating inefficiencies in multiple input and multiple output production correspondences. Following Charnes, Cooper and Rhodes (CCR, 1978) a number of different DEA models have now appeared in the literature (Seiford and Thrall, 1990). During the period of model development, the economic concept of returns to scale (RTS) has also been widely studied within the framework of DEA and this, in turn further extended the applicability of DEA. One of the major problems of fish production in Nigeria is that of low productivity and inefficiency in resource allocation and utilization. Improvement of efficiency and fulfillment can be as one of the most effective methods to realize production development.

Firstly, DEA determines the technical efficiency and provide information on how to increase productivity using the same level of resources and this study intends to depart from the common analytical approaches in analyzing technical efficiency by using Data Envelopment Analysis (DEA) for assessing the returns to scale of fish farmers in llorin, Kwara state. This is because DEA uses slacks that is absent in the stochastic production frontiers and this slacks give an accurate indication of technical efficiency measurement (Jatto et al., 2012) and also showed individual returns to scale.

Furthermore, Belbase and Grabowski (1985) and Shapiro (1983) argue that efforts to improve efficiency may be more cost effective than introducing new technologies as a means of increasing agricultural productivity, if farm operators have not used existing technology 
efficiently. Secondly, returns to scale will provide information of whether expansion of scale of fish production done by multiplying capital and variable inputs will have economic impact. Returns to scale also imply economies of scale because of duality in production theory (Jehle and Reny 2001; Pindyck and Rubinfeld 1998). The outcome of this study is expected to be able to provide significant contributions for improving fish production.

\section{METHODOLOGY}

The study was conducted in llorin, the kwara state capital, chosen based on predominance of registered fish farmers in the state. A random sampling technique was adopted in selecting 120 registered fish farmers. Data was collected by administering a structured questionnaire to the sampled farmers. The analysis was done with data envelopment analysis and descriptive statistics.

For this study output oriented DEA as designed by Coelli (1996) and used by Jatto et al. (2012) was used to determine how much input mix the farmers would have to change to achieve the output level hat coincides with the best practice frontier. Technical efficiency will be measured as follows:

$$
\begin{gathered}
\operatorname{Max} \mathrm{TE}=\frac{\sum_{r-1}^{s} \alpha_{r} y_{r o}}{\sum_{r-1}^{m} \beta_{i} x_{i o}} \\
\text { subject to } \frac{\sum_{r-1}^{s} \alpha_{r} y_{r j}}{\sum_{r-1}^{m} \beta_{i} x_{i j}} \leq 1, j=1, \cdots n \\
r=1 \ldots \mathrm{s} ; \mathrm{i}=1 \ldots \mathrm{m} .
\end{gathered}
$$

$\alpha, \beta$ are parameters to be estimated and $x_{i j}$ and $y_{i j}$ respectively are the quantities of the $i^{\text {th }}$ input and $r^{\text {th }}$ output of the $j^{\text {th }}$ farm. As the ratio is maximized it would be constrained to be no greater than one. Thus, if TE equals one, then it is perfectly efficient.

Inputs = fingerlings (numbers); Feed (kg), Labour (man/days)

Output $=$ fish (numbers)

Firm $=1 \ldots n$

\section{RESULTS AND DISCUSSION}

Table 1 showed the summary statistics of distribution of technical efficiency and returns to scale. The result showed that majority (55\%) of the fish farmers operate at an efficiency range of $0.501-0.6$. On average, the technical efficiency of the fish farms is 0.60 ; with less than 18 per cent of fish farms still having efficiency less than the average. Therefore, there was still considerable room for boosting productivity through improving technical efficiency with the existing technology. It could be done by increasing scale of the fish farm, or increasing the number of fingerlings.

The overall mean technical efficiency which was 0.6 implies that on average fish farmers observed output was 0.4 less than the maximum output which can be achieved from the existing level of inputs. In addition, it is an indication of opportunity for improvement in efficiency which could either increase output or reduce cost of production given the present technology and operating close to the frontier (Jatto et al., 2012). The observed efficiency (0.6) can also be attributed to various factors ranging from technical production constraints, socio-economic and environmental factors. Furthermore, it has been argued by Yusuf and Malomo (2007) that non physical inputs like experience, information asymmetry and other 
socioeconomic factors might influence the ability of a farmer to use the available technology efficiently and this agrees with Ojo (2003).

Table 1. Distribution of technical efficiency and returns to scale

\begin{tabular}{|c|c|c|}
\hline Distribution & Frequency & Percentage \\
\hline $0.301-0.4$ & 9 & 8 \\
\hline $0.401-5.0$ & 12 & 10 \\
\hline $0.501-0.6$ & 66 & 55 \\
\hline $0.601-0.7$ & 16 & 13 \\
\hline $0.701-0.8$ & 5 & 4 \\
\hline $0.801-0.9$ & 2 & 2 \\
\hline $0.901-1.0$ & 10 & 8 \\
\hline Total & 120 & 100 \\
\hline Average & 0.6 & - \\
\hline Maximum & 1.0 & - \\
\hline Minimum & 0.3 & - \\
\hline Returns to scale & Frequency & Percentage \\
\hline Increasing & 88 & 73 \\
\hline Constant & 18 & 15 \\
\hline Decreasing & 14 & 12 \\
\hline Total & 120 & 100 \\
\hline
\end{tabular}

Input slacks: This problem arises when it is questionable as to whether a farm is at efficient point on the frontier (Yusuf and Malomo, 2007). If one could reduce the amount of any of the input used and still produce the same output, it is known as input slack which is also referred to as input excess.

The input slacks provide an accurate indication of technical efficiency of a farm by Farrell in Data Envelopment Analysis. On the average; numbers of fingerlings, feeds and labour had slacks of $0.0,6.5$ and 0.4 respectively. These imply that inputs could be decreased by those units and still produce the same level of output. Thus, the fish farmers are said to be inefficient in input usage by the said values. From the result above, numbers of fingerlings and labour is more efficiently utilized, while feed is the most underutilized input. This result disagrees with Yusuf and Malomo (2007) whose result showed that feed is more efficiently utilized and labour is the most underutilized but agrees with Jatto et al. (2012).

The returns to scale showed that majority $(73 \%)$ of the poultry farmers farms are exhibiting increasing returns to scale. This increasing return to scale is an appropriate choice to increased productivity and the biggest observation is that when there are increasing returns to scale a firm's average cost of production is decreasing. The implications of this; is that If one farm with increasing returns to scale is capable of producing enough output for the entire market then there is a barrier to entry because this one farm could produce a level of output that would satisfy the market at less cost than any other firm.

\section{CONCLUSION}

From the analysis estimated from the returns to scale; the average technical efficiency of the fish farmers was 0.6 with an inefficiency of 0.4 . This showed that fish farmers operate at a moderate efficiency score and exhibited an increasing return to scale. It was concluded with the state of technology that there is still room for improvement in fish productivity which can give a double impact: increase in efficiency leads to increase in productivity. With this high level of returns to scale in fish farming, it is recommended that this information should be spread to all the farmers in the study area and other surrounding communities. 


\section{REFERENCES}

[1] Banker, R.D., A. Charnes and W. Cooper (1984).Some Models for Estimating Technical and Scale Inefficiency in DEA. Cited in Ajao, O.A. (2010). Empirical Analysis of Agricultural productivity growth in sub-Sahara Africa: 1961- 2003.

[2] Belbase, K. and Grabowski, R., 1985.Technical efficiency in Nepalese agriculture, Journal of Development Areas, 19: 515-525.

[3] Charnes, A., W. Cooper and E. Rhodes (1978).Measuring the Efficiency of Decision Making Units (DMU), European Journal of Operations Research. 2 (6): 429-444.

[4] Coelli T., E. Grifell-Tatje, and S. Perelman (2001). Capacity Utilization and Short Run Profit Efficiency: Paper presented at the North American Productivity Workshop, June 2000.

[5] Coelli, T. J. (1996).A guide to DEAP version 2.1: A Data Envelopment Analysis Computer Program, CEPA working paper 96/08, university of New England, Australia.

[6] Färe, R., S. Grosskopf, M. Norris and Z. Zhang (1994). Productivity Growth, Technical Progress and Efficiency Change in Industrialized Countries, America Economic Rev., 6(11): 66-83.

[7] Jatto, N.A., M.A. Maikasuwa, S. Jabo, U.I. Gunu (2012). Assessing the Technical Efficiency level of Poultry Egg Producers in llorin, Kwara State: A Data Envelopment Analysis Approach European Scientific Journal 8(27): 110-117.

[8] Jehle, G. A. and P.J. Reny (2001).Advanced Microeconomic Theory, AddisonWesley, Boston.

[9] Ngunyen-thi-thanh, H. (2006).Draft Report on the Use of Data Envelopment Analysis: A Comprehensive Text with Models Cited in Theodoridis, A. M., A. Psychoudakis and A. Christofis (2006).Data Envelopment Analysis as a Complement to Marginal Analysis". Agricultural economics review 7(2): 55-65.

[10] Ojo, S.O. (2003).Productivity and Technical Efficiency of Poultry Egg Production in Nigeria, International journal of poultry science 2(6): 459-464.

[11] Pindyck, R. S. and D. L. Rubinfeld (1998).Microeconomics, Prentice Hall International, Inc. Upper Sadle River, New Jersey.

[12] Salvatore, D., 1996. Managerial Economics in A Global Economy. McGraw-Hill, New York.

[13] Seiford, L.M. and R.M. Thrall (1990).Recent Developments in DEA: The Mathematical Programming Approach to Frontier Analysis. Journal of Econometrics, 46: 7-38.

[14] Shapiro, K.H. (1983).Efficiency differentials in peasant agriculture and their implications for development policies. Journal of Development Studies 19: 179-190.

[15] Theodoridis, A. M., A. Psychoudakis and A. Christofis (2006).Data Envelopment Analysis as a Complement to Marginal Analysis, Agricultural economics review. 7(2):55-65.

[16] Yusuf, S.A. and O. Malomo (2007).Technical Efficiency of Poultry Egg Production in Ogun State: A Data Envelopment Analysis (DEA) approach. International journal of poultry science 6(9): 627-629. 